\title{
Cultura y política en el proyecto filosófico de Peter Sloterdijk. Limitaciones y potencialidades de su esferología
}

\author{
Juan Sordo y Ricardo Guzmán Díaz
}

Se busca generar un acercamiento al proyecto filosófico de Peter Sloterdijk a partir de Esferas, su obra magna, con énfasis en el estudio esferológico de fenómenos culturales que se desprenden de ella y en algunas de sus limitaciones. Se plantea que a pesar del reconocimiento que ha alcanzado, su impacto ha sido escaso en la investigación debido a su distanciamiento radical de las formas y los supuestos básicos del pensamiento filosófico y científico legitimado.

PALABRAS CLAVE: esfera, esferología, Sloterdijk, cultura, ontología pluralista

\section{Culture and Politics in Peter Sloterdijk's Philosophical Project. Limitations and Potentialities of his Spherology}

A general introduction to Peter Sloterdijk's philosophical project is conducted by focusing on his major work, Spheres. An spherological approach to cultural phenomena developed from it is highlighted, while pointing some of its limitations. It is also argued that due to the author's radical detachment from philosophical and scientific legitimized forms and basic assumptions, his influence in research is still far below his recognition.

KEYWORDS: sphere, spherology, Sloterdijk, culture, pluralist ontology

JuAN SoRdo: Tecnológico de Monterrey, Monterrey, Nuevo León, México jc.sordo.phd.mty@itesm.mx

Ricardo Guzmán Díaz: Tecnológico de Monterrey, Monterrey, Nuevo León, México

rguzman@itesm.mx

Desacatos, núm. 41, enero-abril 2013, pp. 139-154

Recepción: 5 de diciembre de 2011 / Aceptación: 21 de junio de 2012 
$\mathrm{L}$ a obra y la figura pública de Peter Sloterdijk no se ajustan a la imagen común del filósofo académico. Las ideas, el estilo personal, la elección de temas, las referencias y los conceptos del también rector de la Universidad de Arte y Diseño de Karlsruhe y moderador del programa de debate de la televisión alemana "Im Glashaus: Das Philosophische Quartett” le han acarreado, además del reconocimiento, fuertes cuestionamientos e incluso controversias mediáticas. ${ }^{1}$ Su Crítica de la razón cínica de 1983 le valió los elogios de Habermas y el distintivo de la gran promesa de la nueva "teoría crítica", pero su renuencia a alinearse como pensador de izquier$\mathrm{da}$ - al criticar el proyecto humanista y retomar ideas de Nietzsche y Heidegger, ambos asociados con el nazismo- y la radicalización de su cuestionamiento al statu quo del mundo filosófico lo convirtieron en un autor incómodo para la elite intelectual en Alemania. Su incursión posterior en terrenos considerados "oscurantistas", su prosa cargada de intensidad literaria y la experimentación conceptual presente en varias de sus obras sólo abonaron a esta tensión. Las opiniones más difundidas sobre Sloterdijk, ventiladas en medios de amplia circulación y en las que se revela un escaso conocimiento de su producción ensayística, insisten en discutir si la celebridad que ha alcanzado corresponde al valor de su obra o si se debe más a su estilo polémico y seductor. Sin embargo, es cada vez más abundante una reflexión seria en torno a su trabajo y en distintas universidades del mundo comienzan a ser frecuentes los cursos y las tesis que examinan su pensamiento.

En España, como en Francia y Holanda, la primera polémica protagonizada por Sloterdijk impulsó su difusión, y desde entonces gran parte de su obra

\footnotetext{
${ }^{1}$ La más conocida fue en torno a su conferencia "Normas para el parque humano" (1998, publicada el año siguiente), en la que declara clausurado el proyecto humanista y por la que fue acusado de revivir el plan y los conceptos del nazismo (Fehrmann, 2001). En la más reciente, calificó como cleptocracia al Estado de bienestar y propuso sustituir el sistema tributario por uno de aportaciones voluntarias (Poch, 2009).
}

ha estado disponible en español con prontitud, contrario a lo ocurrido en lengua inglesa. ${ }^{2} \mathrm{~A}$ pesar de esta accesibilidad, de que se ha extendido la opinión de que es "uno de los filósofos actuales más apasionantes e influyentes" (Solares, 2010: 3) y del reconocimiento y legitimidad que ha alcanzado, ${ }^{3}$ en México es aún poco conocido entre los estudiosos de los campos social y humanístico. Este artículo busca generar un acercamiento a sus ideas, especialmente a la trilogía Esferas, y argumentar que pueden extraerse de ella importantes directrices para el estudio de fenómenos culturales concretos.

\section{EL PROYECTO FILOSÓFICO SLOTERDIJKIANO}

La obra de Sloterdijk, explícitamente desmarcada de la racionalidad ilustrada, puede ubicarse, grosso mo$d o$, dentro de un pensamiento de la complejidad con orientación fenomenológica. Por ella desfilan los grandes temas del presente, como la globalización, el mundo tecnológico, la crisis de la modernidad y la sociedad mediatizada. Esto podría colocarlo como uno más de la pléyade de autores "posmodernos", pero se distingue por mantener su postura crítica ante las tendencias intelectuales en boga y por estudiar los fenómenos desde enfoques o aspectos generalmente pasados por alto. Formado inicialmente a la estela de la Escuela de Frankfurt — con la que luego rompería- y declarado continuador de

\footnotetext{
${ }^{2} \mathrm{La}$ escasez de traducciones al inglés ha limitado su difusión en el ámbito académico internacional. En esta lengua, después de la aparición de sus dos primeras obras a finales de la década de 1980 hubo una ausencia de casi 20 años, interrumpida recientemente por un "segundo arribo" de Sloterdijk (Elden y Mendieta, 2009) con nuevas traducciones, artículos en inglés del propio autor, números especiales en Cultural Politics: An International Journal (2007) y Environment and Planning D: Society and Space (2009) y la traducción del primer volumen de Esferas en 2011.

${ }^{3}$ Una figura de la talla de Bruno Latour ha acogido y valorado su pensamiento y lo ha calificado como "el gran pensador alemán" (Latour, 2010: 74). Ha recibido el premio "Sigmund Freud" de prosa científica en 2005 y el nombramiento como Commandeur de l'Ordre des Arts et des Lettres de la República francesa en 2006.
} 


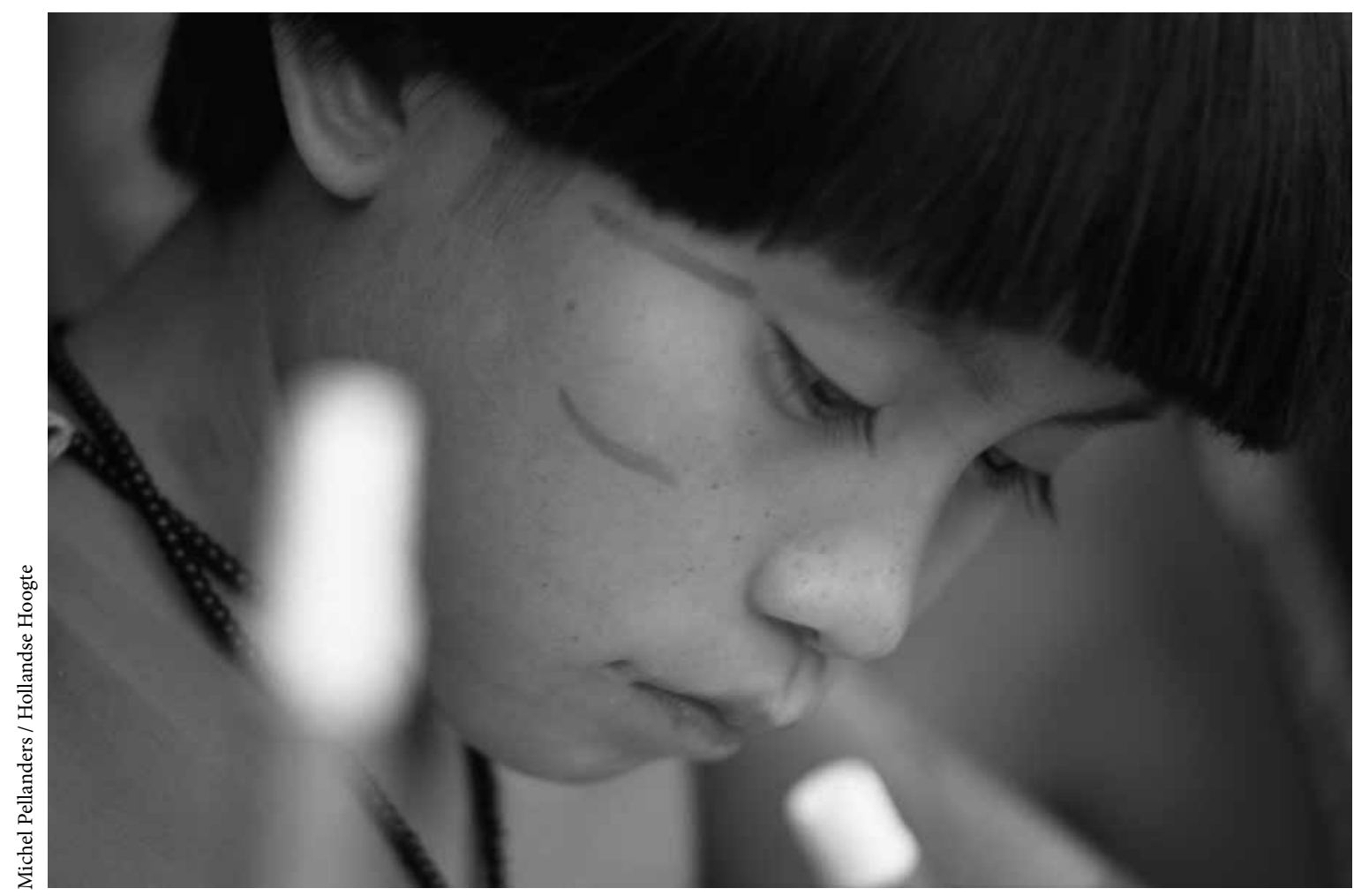

Muchacha yanomami pinta con lápices con punta de fieltro. Tootobi, Roraima, Brasil, 1996.

las obras de Nietzsche y Heidegger, muestra también una influencia clara del pensamiento francés contemporáneo y reciente. Sus conocimientos son amplios no sólo en el campo de la filosofía, sino en otros, como la antropología, la historia, el arte y la etnología. Además, reivindica producciones intelectuales desdeñadas en el mismo mundo occidental y muestra erudición sobre las tradiciones del mundo oriental y medio-oriental. ${ }^{4}$

Sloterdijk se distingue también porque su reflexión sobre el presente y el futuro de la humanidad mira constantemente al pasado, dialoga con soltura tanto con pensadores de épocas remotas como con sus contemporáneos. Así, va tejiendo campos semánticos y referenciales propios, echando mano de

\footnotetext{
${ }^{4}$ El estudio que mantuvo con el gurú Rajneesh durante su residencia de varios años en India es conocido y sus referencias a mitos orientales y a tradiciones taoístas o védicas son frecuentes.
}

disciplinas tan dispares como la teología, la cibernética, el psicoanálisis, la biología o la arquitectura, pero sin seguir modelos interdisciplinarios esquemáticos. Es especialmente crítico hacia el proyecto europeo de la Ilustración, pero no deja de extraer consecuencias de éste. Considera sus supuestos ontológicos más básicos anclados aún en la tradición metafísica que se proponía abandonar. Señala en $E l$ sol y la muerte ${ }^{5}$ que el pensamiento occidental moderno, al identificar con lo real "aquello y sólo aquello que se puede aprehender de manera objetiva y aislada, aquello que tiene presencia material y formal [...] las cosas aisladas, los objetos y personas corporales individuales" (Sloterdijk y Heinrichs,

\footnotetext{
${ }^{5}$ Volveremos constantemente a esta obra - diálogos entre Sloterdijk y Hans-Jürgen Heinrichs-, pues en ella se analiza con detalle el contenido, las motivaciones y las reflexiones del autor respecto de Esferas I y II, y lo que anticipaba sería Esferas III.
} 
[2001] 2004: 139), continúa atado a un "fetichismo de la sustancia", incapaz de atender de manera adecuada cuestiones antropológicas de tipo medial o presubjetivo que califica de primordiales. Dirige a éstas su atención y propone una ontología pluralista y relacional -en la que "las consecuencias son más fundamentales que los fundamentos" (Sloterdijk, [2004] 2009b: 378)—, que desarrolla y justifica ampliamente, así como una mayor observación a las realidades sutiles e inmateriales.

Pero a la limitación conceptual y temática que la tradición sustancialista supone, la profesionalización de la filosofía en la academia añadirá una exigencia de seriedad y un empobrecimiento de repertorios lingüísticos, que según Sloterdijk la reduce a una mera circulación de argumentos rigurosos, estéril más allá de la lucha por cotos de poder en las universidades. Aboga entonces por la recuperación del carácter amateur del quehacer filosófico - sin abandonar por ello el rigor-, lo que se concreta en la práctica y defensa de una pluralidad de formas discursivas- y metodológicas - una libertad estilística e interpretativa, pero en referencia constante a escenas concretas identificables, además de la búsqueda de espacios de traslape de significados entre los saberes de distintos orígenes -.${ }^{7}$ De esta forma, procura acceder a una filosofía en conexión más íntima con los avatares de la humanidad, que contribuya al saber vivir individual y colectivo, y en última instancia a una posible y necesaria orientación filosófica de la acción política.

\section{ESFERAS: EL HOMBRE Y SUS ESPACIOS DEVIDA}

Esferas da título a la voluminosa trilogía considerada la obra más importante de Sloterdijk. En ella se profundizan ideas ya presentadas en publicaciones de menor envergadura, como En el mismo barco o Extrañamiento del mundo, y su experimentación estilística alcanza uno de sus puntos más logrados. Ensayamos a continuación una caracterización general de la obra, para después hablar de los saberes que confluyen en el concepto esfera, las dimensiones a las que alude, así como los momentos de formación esférica que pueden identificarse.

En el pensamiento de Sloterdijk, la noción de esfe$r a$ representa la forma abstracta de designar las condiciones en que es posible el despliegue de la vida propiamente humana. En las más de 2000 páginas de la obra va extrayendo un saber acumulado en el uso de este concepto por las tradiciones teológica y metafísica - sin sus pretensiones totalizadoras-, y lo dilata con esclarecimientos que varias disciplinas han aportado sobre las necesidades materiales y simbólicas para el mantenimiento de la vida humana y con las formulaciones de algunos de los filósofos y teóricos más arriesgados de los últimos dos siglos.

\footnotetext{
6 "Dejo así que la ontología empiece con el número Dos" (Sloterdijk y Heinrichs, [2001] 2004: 147), afirma Sloterdijk para subrayar que lo más fundamental de la realidad son las relaciones o las situaciones que implican al menos dos elementos y no los elementos individuales relacionados.
}

\footnotetext{
${ }^{7}$ Lo que Henrichs describe como un ensanchamiento del sujeto cognoscente (Sloterdijk y Heinrichs, [2001] 2004: 158-159).
} 
La esfera se convierte en la directriz de una empresa ambiciosa: explorar y reconstruir los procesos de hominización que operan tanto en el plano de cada ser humano como en la travesía de la especie a lo largo de su historia. En Esferas se plantea al mismo tiempo "una onto y filogénesis de los espacios de vida humana" (Safranski, [2003] 2009: 16) y una "ciencia histórica de lo anímico" (Sloterdijk y Heinrichs, [2001] 2004: 279).

$\mathrm{Al}$ rechazar la idea del hombre como originariamente individual y naturalmente proclive a la socialización, presente en la mayoría de los sistemas de pensamiento sociológico y político, ${ }^{8}$ Sloterdijk comienza esa historia de lo anímico antes de la consolidación del individuo como tal. Considera que la subjetividad y la dimensión gregaria deben ser explicadas por medio del modo en que tuvo $-\mathrm{y}$ tiene- lugar su instauración. Descarta para ello la mitología del contrato social y la metáfora organicista (Sloterdijk, [2004] 2009b: 202-235). A la pregunta sobre la constitución primaria de la condición humana, Sloterdijk responde con una noción espacial-relacional: "Los hombres están, antes que nada, insertos en una esfera bipolar, un espacio relacional íntimamente afinado que sólo puede existir en virtud de la vinculación y adhesión de lo que vive en común" (Sloterdijk y Heinrichs, [2001] 2004: 144). Se trata de "una verdad de Perogrullo, [pero] ignorada sistemáticamente por la modernidad ilustrada que alumbró las ciencias sociales" (Castro, 2005: 96): los humanos no están nunca, ni pueden estar, solos; ser humano consiste en encontrarse contenido en interioridades protectoras sutiles que se generan por el acompañamiento de dos o más. Esferas reconstruye con paciencia el pasaje de una especie animal más abierta al mundo a una especie naturalmente artificial -el homo sapiens_-, de manera

\footnotetext{
8 "Si los seres humanos pueden coexistir en 'sociedad' es sólo porque ya en otra parte están vinculados y remitidos uno a otro [...] Sin una previa sintonización psicotópica los reunidos no serían reunibles" (Sloterdijk, [2004] 2009b: 232).
}

paralela al proceso de transformación de un ser vivo prematuramente parido en un ser de vida anímica intensificada. Para tal fin se describen y analizan diversas formas concretas en que los humanos generan para sí mismos y sus acompañantes una especie de clima interior de contención, animación e inmunidad - comparado con la imagen del invernaderoque no se corresponde con un espacio físicamente existente, sino que podría denominarse cosubjetivo, vivenciado o surreal.

\section{SABERES QUE CONFLUYEN EN EL CONCEPTO ESFERA}

Esta empresa filosófica se apuntala, entre otros, sobre cuatro saberes en torno al hombre que van siendo articulados por la pluma del filósofo. Uno de ellos proviene de las nociones de la especie humana como biológicamente inacabada y prematura, desarrolladas en extenso en la antropología, ${ }^{9}$ que condicionan una relación más compleja entre el humano y su mundo que el acoplamiento entre otros animales y sus entornos: "Somos paridos, pero demasiado pronto. Somos criaturas abortadas, arrojadas a un mundo sólo parcialmente establecido, aún por ser completado" (Elden y Mendieta, 2009: 9-10). Esto, al ampliar la necesidad de cuidados y la dependencia respecto de los otros, conduce al autor a considerar el desarrollo de la especie como "un acontecimiento espontáneo de autocrianza" (Sloterdijk y Heinrichs, [2001] 2004: 62).

Por otra parte, la esferología retoma la noción de un espacio vivencial de la existencia humana, desarrollada por Bachelard en su Poética del espacio ([1957] 2011), que Sloterdijk también localiza

\footnotetext{
${ }^{9}$ El hombre como animal inacabado (Gehlen, [1940] 1987) y la noción de neotenia de Jules Kollmann (citada en Gould, [1977] 2010: 411-468). Sloterdijk lo reinterpreta en un sentido positivo, designa al hombre como surgido del mimo y el lujo que le permite sobrevivir a esa fragilidad biológica (Sloterdijk, [2004] 2009b: 529-538)
} 


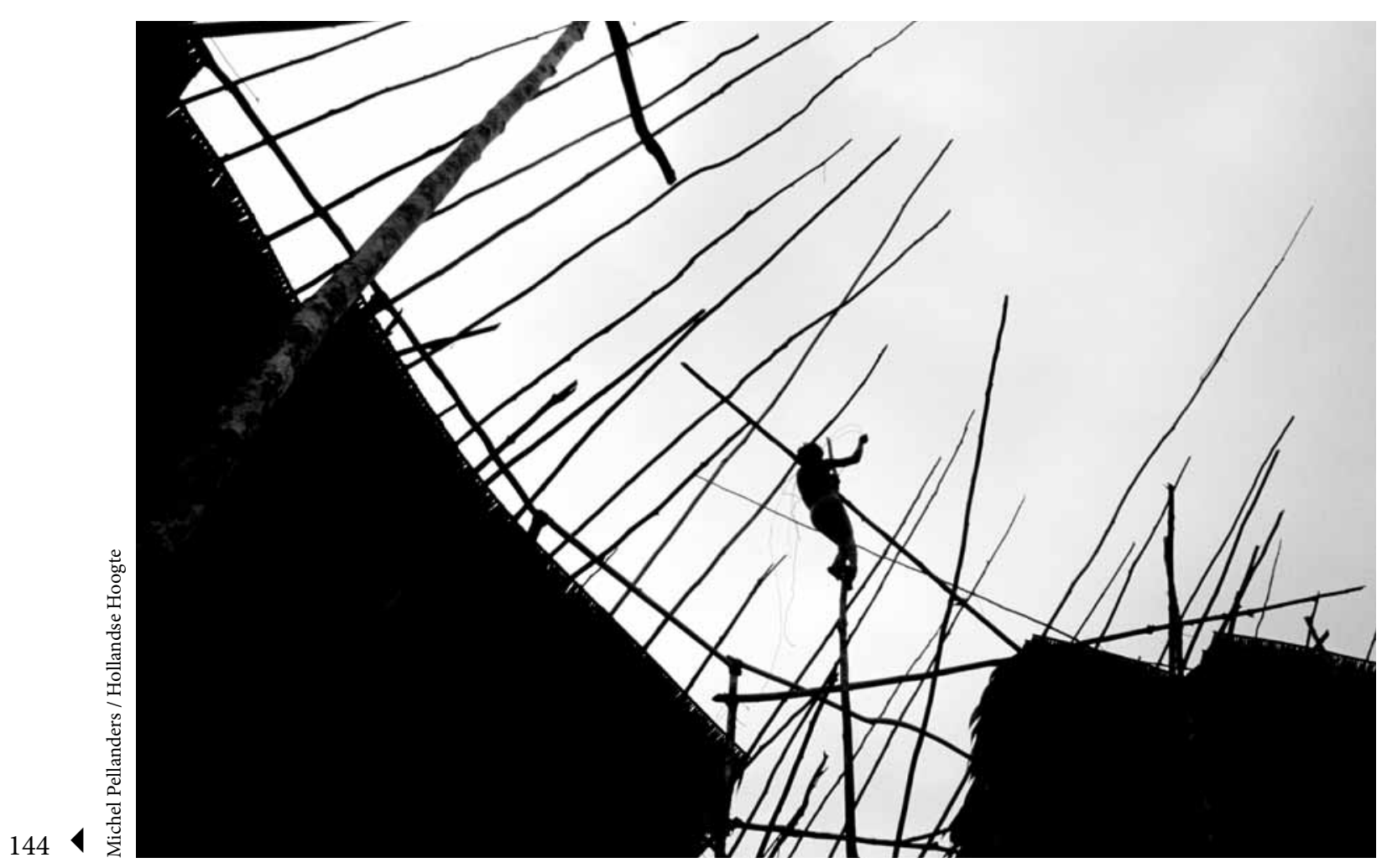

Hombre yanomami construye una maloca, cabaña, aldea. Demini, Roraima, Brasil, 1989.

intuida -mas no explicitada - por Heidegger en su famosa expresión "ser(estar)-en-el-mundo" en Ser y tiempo (Heidegger, [1927] 2009). ${ }^{10}$ Reconoce en ella una de las elaboraciones más agudas que permiten aprehender algo de la casi inobjetiva experiencia de esa espacialidad $-\mathrm{o}$ situacionalidad- primaria de lo humano.

Sloterdijk también echa mano de formulaciones psicoanalíticas sobre las fuentes intersubjetivas de la vida anímica, es decir, de los procesos más tempranos y profundos de subjetivación, ineludiblemente inscritos en relaciones que proveen contención y referencialidad, así como de las nociones freudo-lacanianas de transferencia y medialidad. Además, pone

\footnotetext{
${ }^{10}$ También en sus conferencias "Construir, habitar, pensar" y “... poéticamente habita el hombre..." pronunciadas en 1951 y publicadas en Conferencias y artículos (Heidegger, [1954] 2001: 7-119 y 139-152).
}

en relación estos desarrollos teóricos con sus anticipaciones en tradiciones místicas y magológicas previas.

Por último, en Esferas se consideran los esclarecimientos tecno-científicos recientes sobre las precisas y frágiles condiciones requeridas para el mantenimiento de la vida - en particular de la humana- ignoradas durante siglos. Paralelo al conocimiento de las condiciones ambientales en su sentido físico y material, que implican un sistema biológico de inmunidad más complejo de lo que antes se concebía, ${ }^{11}$ se han aclarado las realidades culturales como sujetas a procesos constructivos y estabilizadores de condiciones de vida. Ambos tipos

\footnotetext{
${ }^{11}$ Ante mayor conocimiento de su funcionamiento revela mayores peligros; además, requiere la presencia de lo extraño o dañino en su mismo medio organísmico para operar con algún grado de éxito (Sloterdijk, [2004] 2009b: 153-162).
} 
de atmósferas, sacadas a la luz en buena medida a partir de procesos destructivos que las ponen en riesgo, orillan a abogar por una "continua atención a la respirabilidad del aire: primero en sentido físico, pero, después, también, y progresivamente, en relación con las dimensiones metafóricas de la respiración en espacios culturales" (Sloterdijk, [2004] 2009b: 134).

\section{DIMENSIONES DE LO ESFÉRICO}

El concepto esfera puede pensarse como multidimensional, pues con él se hace referencia a aspectos diversos de la condición humana que, aunque íntimamente relacionados, pueden considerarse de forma aislada para mostrarlos con mayor relieve. En primera instancia se encuentra una obvia dimensión topológica. La esfera es una espacialidad vivencial que se genera por, o más precisamente es en sí misma, la relación que contiene. Su papel fundamental en la hominización condiciona que la existencia humana sea siempre dentro o en. Dado que la subjetivación comienza en una situación de contención originaria - en el vientre materno, en la relación fuerte-, se instaura la necesidad de reconfigurar continuamente como interioridad contenedora el espacio exterior al que se es expulsado, de lo que el nacimiento es sólo el primer acontecimiento de una serie que se prolonga a lo largo de la vida. ${ }^{12} \mathrm{En}$ otras palabras: "los seres humanos están condenados a la producción de [un] interior" (Sloterdijk, [2004] 2009b: 301), que tiene "sólo paredes de distancia y tejados de solidaridad" (Sloterdijk, [2004] 2009b: 277).

Por otra parte, que lo humano sólo pueda tener lugar al interior de esferas supone una dimensión medial. Los modelos generalmente aceptados de comunicación entre individuos psíquicamente autónomos no ofrecen un asidero adecuado para

\footnotetext{
12 Para un desarrollo filosófico más afinado al respecto véase Tuinen (2009).
}

entender los procesos de hominización. Desde la esferología, por el contrario, se consideran más básicas las situaciones de participación preobjetales y presubjetivas de las que el sujeto individual emerge como un producto secundario. Las esferas son espacios de circulación y resonancia en la que los humanos se van distinguiendo unos de otros, al tiempo que se tornan permeables, abiertos y penetrables a las informaciones y los ánimos que circulan en ellas: “Todos los hombres son medios" (Pérez Gay, 2010: 17), o en otras palabras, "el nivel más profundo del sí mismo corresponde a una radical esfera de participación con/por otros" (Castro, 2009: 88).

En esta dimensión se concreta la crítica de la filosofía sloterdijkiana a la referida tradición sustancialista. La pareja, o más precisamente la estructura dual cosubjetiva, ese entre o ese con, se revela más arcaica y primaria que la individualidad. Psíquico, anímico o subjetivo son formas de nombrar no un rasgo de los organismos humanos aislados, sino una disposición que se instaura por la "participación en un campo bipolar o multipolar" (Sloterdijk, [1998] 2009a: 58), por la sostenida contención en situaciones de acompañamiento exacerbado. Por ello, a pesar de su largo desarrollo y de su intensificación en las sociedades avanzadas:

\footnotetext{
bajo las máscaras petrificadas de la cultura de la autonomía, resurgen ahora de nuevo, igual que antaño, los plasmas de las antiguas formas de experiencia invasoras, de los viejos modelos de experiencia obsesivos, participativos y penetrantes. Una situación que, como es natural, Hollywood conoce mucho mejor que la filosofía académica (Sloterdijk y Heinrichs, [2001] 2004: 160).
}

Finalmente, una concepción esférica supone una importante dimensión inmunológica. Ese espacio cosubjetivo a la vez que convierte a sus habitantes en seres permeables, excitables -en última instancia, sentimentales y políticos-, les brinda protección, una interioridad o un cobijo igual de necesario y efectivo tanto en el nivel material más concreto 
como en sus manifestaciones más puramente simbólicas o abstractas. Sloterdijk desarrolla este sentido de lo esférico en los siguientes términos:

me ayudo de un metalenguaje común tomado de la inmunología. Y aplico este concepto inmunológico hasta el punto de extenderlo a sistemas técnicos de seguridad y sistemas de aseguramiento vital jurídicos, terapéuticos, médicos y biológicos. A éstos se añaden construcciones de inmunidad semánticas, imaginarias o poéticas (Sloterdijk y Heinrichs, [2001] 2004: 218).

Así, de la fragilidad biológica del animal humano - y de su ampliación a medida que crece la dependencia respecto de los otros- se desprende una fragilidad que podría denominarse psíquica, que desde los albores de la hominización de la especie la ha hecho proclive a rituales, creencias e imágenes del mundo que le brindan la experiencia de contención y protección o, como señala Vásquez Rocca, "un sistema inmunitario simbólico que construye una película protectora en torno al ser humano" (Vásquez, 2008: 317).

\section{BURBUJAS, GLOBOSY ESPUMAS}

El mundo esferológico no es, sin embargo, un reino sólo de cobijo y tranquilidad. Las esferas están sujetas siempre al riesgo de estallar, lo que eventualmente se traduce en crisis vitales o históricas - la pérdida de la pareja, la disolución de un grupo, la desaparición o el abandono forzado de la nación, la caída de un sistema cosmológico- que pueden dejar a los hombres en el desamparo de la falta de cubiertas. Pero este principio de la esferología va de la mano de otro fundamental: la posibilidad de traslado de la interioridad climatizada -léase acondicionada adecuadamente para el despliegue de la vida humana- de unas esferas a otras. ${ }^{13}$ Generación, destrucción y traslado son

\footnotetext{
${ }^{13}$ En otro sentido, con base en la noción psicoanalítica de transferencia de los afectos de una relación de objeto a otra, Sloterdijk plantea la posibilidad de traslado de las disposiciones aprendidas para compartir esa interioridad en una situación esférica a otra diferente.
}

pues los ejes de la transformación de las esferas. Además, aunque en lo esencial se mantiene en el tiempo la necesidad de los mismos procesos esferopoiéticos que permitieron la aparición de la especie, éstos pueden tomar variadas formas según el momento histórico en que tienen lugar, insertándose en proyectos políticos, ideológicos, teológicos, culturales o sociales diversos. La estructura de Esferas como trilogía busca dar testimonio de ello y cada tomo estudia un nivel o momento paradigmático. Escuetamente, el primer volumen trata de la formación originaria de esferas en lo íntimo y lo cercano; el segundo recorre las sucesivas ampliaciones a las que la interioridad esférica puede ser sujeta, llegando a la pretensión de una monósfera global. En el último volumen se describe la multiplicidad de esferas diversas y polimorfas que sobrevienen tras la implosión de la macroesfera única y que se agrupan en conformaciones en apariencia caóticas al modo de espumas. En el primer tomo, subtitulado Burbujas: Microesferología ([1998] 2009a), se analizan las formaciones esféricas más originarias, las que instauran que el estar humano sea en todo momento un estar-con. Contrario a otros autores desencantados como él del proyecto de la Ilustración y con una formación intelectual similar que conciben la condición humana como una soledad insuperable o una incomunicación radical, Sloterdijk identifica la solidaridad, la apertura, la capacidad de resonancia psíquica y emocional como situación humana primera. En ese tenor se examinan distintas concretizaciones de esos "pequeños mundos de frágiles paredes de las alianzas de pareja, de la participación simbiótica o de la resonancia íntima" (Sloterdijk y Heinrichs, [2001] 2004: 178): la diada madre-hijo y sus anticipaciones prenatales, la pareja enamorada, las arcaicas animaciones del humano capturadas en los mitos de la creación, entre otros. La relación fuerte, la instauración de la penetrabilidad anímica del humano, es la protagonista de esta parte de la obra. Ese "espacio de aprendizaje [del sentimiento inclusivo] que posee la capacidad de crecer" (Sloterdijk, [2004] 2009b: 17). 
Esferas II. Globos: macroesferología ([1999] 2004) es un recorrido por la inmensidad de las conformaciones esféricas de los grandes colectivos, sus mecanismos de ampliación y sus pretensiones de totalidad. Se trata de "un gran relato de la expansión de lo anímico en la serie ininterrumpida de las ocupaciones imperiales y cognitivas del mundo" (Sloterdijk, [2004] 2009b: 16-17), cuyo funcionamiento consiste en definir un contorno en expansión constante y en mantener la ilusión de un punto o fuego central de animación común. En él se analizan algunos de los mecanismos técnicos, políticos y cognitivos que permiten los traslados de la atmósfera de familiaridad de lo íntimo y lo pequeño a lo público y lo enorme; la absoluta realidad y necesidad que adquieren para los colectivos humanos las formas simbólicas o abstractas de inclusión y protección; y, por otra parte, la inviabilidad del proyecto de establecer estos sistemas inmunitarios de manera total y centralizada. Se muestra que, tras el aumento de escala, lo que en la microesfera es sólo necesidad de cobijo en formas más bien difusas se vuelve objeto de rigurosa construcción técnica, arquitectónica, geométrica o lógica. Las complicadas disquisiciones metafísicas o la rebuscada arquitectura, hoy tomadas por absurdos o caprichos, aparecen bajo la mirada del filósofo como formas creativas de procurar ese cobijo inmunitario de las que el hombre contemporáneo podría aún aprender.

Esferas III. Espumas: esferología plural ([2004] 2009b) parte de la constatación de la implosión de la macroesfera y de la imposibilidad de una globalización total de la humanidad. A partir de la metáfora polisémica de la espuma, Sloterdijk presenta una caracterización de las formas de organización de las espacialidades cosubjetivas en los tiempos de la mundialización de las comunicaciones y los intercambios bajo la noción de las multiplicidades coaisladas y cofrágiles. La espuma representa la posibilidad de coexistencia de diversas esferas cuyas paredes las separan y las comunican a la vez y que al embonar unas con otras generan configuraciones en apariencia caóticas, pero que responden a leyes morfológicas y dinámicas en las que "las celdas jóvenes que revientan mueren en cierto modo dentro de sus vecinas, a quienes legan su volumen" (Sloterdijk, [2004] 2009b: 43). Las sociedades, en sentido amplio, son sostenidas mediante procesos difusos de participación estresante conducidos en los medios de telecomunicación masiva - los escándalos mediáticos, los éxitos de las estrellas del pop-donde la idea de una esfera central se halla fuera de lugar. En tanto, al menos en las sociedades más desarrolladas el mimo o el lujo "necesario" y técnicamente asegurado se intensifica y cada vez más seres humanos se instalan en esferas en apariencia individualizadas, tras las cuales persiste una estructura dual de relación, aunque virtualizada "mediante autoemparejamiento, autocuidado [y] autocomplementación" (Sloterdijk, [2004] 2009b: 447), que les permite seguir siendo atmósferas humanamente respirables.

\section{LA ESFEROLOGÍA COMO ORIENTACIÓN PRÁCTICA DE LA INVESTIGACIÓN CULTURALY LA POLÍTICA EN LA GLOBALIZACIÓN}

Como hemos intentado hacer notar, Esferas representa una profunda reflexión antropofilosófica cuyos planteamientos poseen implicaciones para una amplia gama de ámbitos y problemas. Una de las más relevantes es la posibilidad de estudiar la dinámica cultural en la globalización y sus repercusiones políticas, desde una perspectiva esferológica. La esferología revela el carácter activamente constructivo que subyace a los procesos de hominización y la hibridación que suponen entre lo tecnológico, lo cultural y lo natural, a lo que el filósofo se refiere como antropogénesis. ${ }^{14}$ Ello subraya la alta improbabilidad del surgimiento y mantenimiento de las formas de vida humana efectivamente existentes, por lo complejos, sutiles y

\footnotetext{
${ }^{14}$ Coincide en lo general con planteamientos similares a los de Bruno Latour en referencia a la mediación técnica y la "naturaleza humana" (Latour, 1994), con quien comentábamos que ha habido un acercamiento en los últimos años.
} 
demandantes que resultan dichos procesos. De estas consideraciones se deriva una concepción de las culturas como los invernaderos para colectividades, que no pueden ya ser dados por supuestos sino que son dificultosamente generados y mantenidos. Lo cultural no se concibe como una especificidad ontológica distinta de otros espacios humanos. Se corresponde, en cambio, con las conformaciones esféricas que se mantienen por la prolongación y la estabilización exitosa de inmunidades atmosféricas locales, en un margen intermedio del continuo que va de las esferas íntimas a las que pretenden la universalidad.

"Una filosofía de la cultura como producción de atmósferas" (Sloterdijk, [2004] 2009b: 377) supone constantes antropológicas y líneas de continuidad a pesar de las transformaciones culturales y políticas que se suceden en el tiempo, lo que hace evidente que si bien muchos de los cuidados que los humanos se brindan tienen lugar bajo nuevas condiciones que integran cada vez más mecanismos o artefactos altamente tecnificados, en lo esencial se mantiene la de los proyectos de inmunidad que se manifestaban en formatos nacionales y étnicos. Pero ante esto la globalización no engloba. La red informática global no genera una correspondiente interioridad habitable a escala planetaria: "La esfera que sólo consiste en superficie, no es una casa para todos, sino un mercado para cualquiera" (Sloterdijk, [1999] 2004: 861). Lo que define a la humanidad como totalidad no es en absoluto el sentimiento de coexistencia inclusiva que algunos auguraban, sino la ineludible simultaneidad y, sobre todo, la cofragilidad ante los riesgos comunes. Por tanto:

el desafío psicopolítico característico de la Era Global [...] no sólo consiste en asimilar la debilitación de las tradicionales inmunidades-container étnicas como pérdida de forma y decadencia [...] Lo que realmente está en juego para los posmodernos son diseños exitosos de inmunidad vivibles (Sloterdijk, [1999] 2004: 869-870).

Para responder a ese desafío, aun cuando el autor no se preocupa por presentarlas de un modo sistemático, es posible extraer de Esferas aportaciones y directrices claras. La noción atmosférica puede concretarse como orientación del estudio cultural y guía de la acción política. Para ello, el modelo de la espuma que presentamos en el apartado anterior y que a continuación ampliamos ofrece los lineamientos morfológico-dinámicos de las relaciones y los procesos culturales actuales. En primer lugar, la espuma supone que el mundo cultural se encuentra constituido por múltiples microesferas o burbujas de diversa dimensión, que tienden a modificarse y desplazarse, a surgir y desaparecer constantemente, que se aglomeran en "asociaciones agitadas y asimétricas de multiplicidades-espacios y multiplicidades-procesos" cohesionadas sólo provisional y precariamente en un "ensamblaje interactivo" (Sloterdijk, [2004] 2009b: 49, 51).

Las espumas no poseen punto central ni márgenes estables. Tampoco es posible una mirada exterior totalizadora, sino que cada una de sus burbujas es 
un contexto específico, con su propia perspectiva: son multifocales. Las burbujas de la espuma son "comunidades de supervivencia" (Sloterdijk, [2004] 2009b: 50-51), ya sean parejas, hogares, asociaciones o comunidades de distintos tipos y, a la vez, atmósferas ligeras y móviles, sujetas a expansión o decrecimiento, transportables. Los dos principios básicos que rigen la relación entre las microesferas de la espuma son el coaislamiento y la cofragilidad. Ante la simultaneidad planetaria, esos mundos se amontonan unos contra otros, forzándose a compartir las membranas que los delimitan, como en las formas de "separación y trabazón de espacio de la arquitectura moderna" llamadas "connected isolation" (Sloterdijk, [2004] 2009b: 197). Ello supone que "limitan unas con otras [...] sin ser realmente accesibles unas para otras, ni efectivamente separables" (Sloterdijk, [2004] 2009b: 50) y que cualquier modificación en una de ellas afecta siempre a sus vecinas.

A diferencia de la popular noción de modernidad líquida de Bauman (2000), en la que se echa de menos cualquier estructura o asidero referencial para orientar la vida humana, el modelo de la espuma permite pensar en conformaciones morfológicas y estructuras de relación, aún en constante transformación, lo que mantiene abierta, bajo nuevas reglas de juego, la posibilidad de regeneración o reconstrucción. Por su parte, la noción de sociedad-red, ${ }^{15}$ aunque útil para comprender la dinámica de los intercambios de información y de la generación de riqueza y poder en nuestra era, carece de una reflexión antropológica sólida que la fundamente. Por ello, a diferencia de la esferología, acepta como válidas nociones sociológicas y políticas que presuponen al hombre sin explicar su génesis. El mismo Sloterdijk señala que la imagen de la red se basa en "una geometría sobremanera reductiva" (Sloterdijk, [2004] 2009b: 197) que no tiene en cuenta la espacialización en la que debe encontrarse cualquier ser humano o colectivo que entre en conexión con

\footnotetext{
${ }^{15}$ Nos referimos a la propuesta por Castells ([1996] 2001), uno de sus principales teóricos y difusores.
}

otros. Todo lugar en donde finalmente "la gente sigue viviendo" (Castells, [1996] 2001: 461) resulta exterior a la red y sus flujos. De ahí que la esferología y su concretización en la espuma pueda captar más acertadamente a nivel vivencial la crisis epocal actual como un desfase profundo entre "la forma global del mundo y las psiques locales" (Sloterdijk, [1993] 2008: 73), como la incapacidad generalizada de los seres humanos para encontrarse realmente en su sitio y con los suyos. Ante ello, el filósofo debe:

impulsar un debate en torno al espacio humano que es digno de ser habitable; tiene que convertirse en inmunólogo de la cultura, y arrostrar la pregunta de cómo este invernadero humano puede instalarse y climatizarse (Sloterdijk y Heinrichs, [2001] 2004: 215).

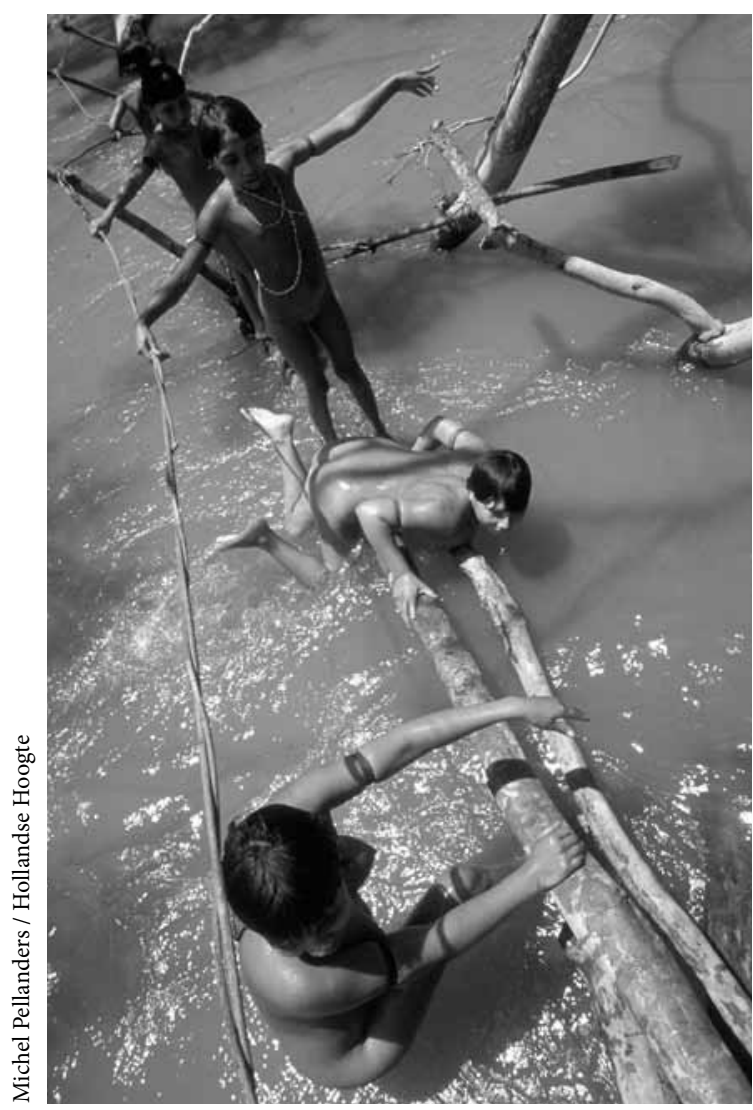

Los yanomami del pueblo de Tootobi construyen un puente sobre el río. Roraima, Brasil, 1996. 
Una política cultural que se ocupe sólo de la conservación de productos culturales resulta trivial ante las implicaciones derivadas de la articulación entre cultura y política ${ }^{16}$ que se desprende de una visión esferológica. Al reconocer lo cultural como un recurso escaso del que depende la supervivencia y destino de los colectivos humanos, pero factible de ser sujeto a mecanismos para su cultivo, traslado y amplificación, "podremos interpretar esta carpa de oxígeno que llamamos cultura y en donde existimos, por un lado, de un modo más cuidadoso y, por otro, más técnico de lo que hacemos en general" (Sloterdijk y Heinrichs, [2001] 2004: 215). Bajo esta perspectiva, la política, más allá del juego del poder, se muestra como una tarea esencialmente técnica - pero también ética - de generación de espacios habitables, de posibilitación de condiciones para la humanización y de administración de recursos limitados de solidaridad. Esferas aboga por superar la separación artificial — promovida por el pensamiento cientificista ilustrado- de los planteamientos de la sociología y la política de aquellos desarrollados desde la etnología, la psicología, la antropología y más aun del estudio de la técnica. Lo político, lo social o lo cultural, nos recuerda la esferología, sólo puede entenderse cabalmente en relación con lo íntimo y lo familiar, y esta relación se manifiesta ante todo como procesos técnicos de amplificación y difusión de modos de coexistencia.

\section{LIMITACIONESY POTENCIALIDADES DE LA ESFEROLOGÍA}

Tras haber valorado positivamente la obra principal de Peter Sloterdijk es preciso considerar ahora sus limitaciones. Dado lo ambicioso del proyecto, sus tensiones son abundantes y diversos los sentidos en

\footnotetext{
${ }^{16}$ Como lo planteara Sloterdijk en otro sitio: la política es "el arte de mantener unidos a los hombres [...] para una buena vida común" (Sloterdijk, [1993] 2008: 14).
}

que pueden planteársele cuestionamientos. ${ }^{17}$ En nuestro caso, buscaremos mostrar que una excesiva atención al primer mundo capitalista conduce al filósofo a una forma parcial de caracterizar el modelo de la espuma que no permite desarrollar plenamente sus potencialidades para el estudio de la realidad cultural contemporánea. Argumentamos que la mayor atención a un contexto sociocultural como el latinoamericano puede contribuir a corregir esta debilidad. Hasta el momento de la publicación de $E l$ sol y la muerte (2001), la irrupción de la espuma tras la implosión de las esferas clásicas o tradicionales y la imposibilidad de un cobijo efectivo en formato planetario era planteada como una situación en términos de crisis y limitación:

muchos de los hombres del siglo $\mathrm{xx}$ fueron arrastrados por transformaciones catastróficas sin haber podido encontrar o desarrollar los medios psíquicos adecuados para trabar intimidades [...] El carácter inhóspito de las relaciones modernas convierte todo tipo de intimación en algo precario. Los sentimientos positivos transferibles a la patria y a la familia se han convertido en un recurso escaso (Sloterdijk y Heinrichs, [2001] 2004: 186).

Sloterdijk hacía aún eco de su preocupación, expresada años antes, sobre la inviabilidad de la progresiva individualización de los espacios humanos, pues este proceso “destruye más 'reservas' humanas y naturales de las que él mismo puede producir o regenerar" (Sloterdijk, [1993] 2008: 101). Ante esta circunstancia de escasez de buen clima interior y de las menores posibilidades para cultivarlo, las burbujas que conforman las espumas se insinuaban heterogéneas y las relaciones entre ellas diversas y complejas, justamente por la necesidad de ampliar

\footnotetext{
${ }^{17}$ Se ha argumentado, por ejemplo, que el fundamento espacial de la existencia humana podría presentarse bajo formas distintas a lo esférico en un contexto como la China tradicional (Thrift, 2009), o bien, que no son suficientemente explícitos los mecanismos sociales que operan el paso de la micro a la macroesferología (Castro, 2009).
} 
al máximo su capacidad de integrar cualquiera de las "zonas habitables por el hombre" (Sloterdijk y Heinrichs, [2001] 2004: 214) que lograra generarse y eventualmente poder transferir lo más eficientemente posible su atmósfera hacia otras esferas. Sin embargo, el contenido finalmente publicado en Esferas III es en buena medida inconsistente con estas expectativas. ${ }^{18}$ En primera instancia, afronta la situación contemporánea con un talante mucho más optimista, ${ }^{19}$ aunque no resuelve realmente las dificultades recién señaladas. Ese optimismo se basa en una equiparación reduccionista entre procuración de cuidados humanos y lujo, ${ }^{20}$ entendiendo este último cada vez más en términos de abundancia de posibilidades de consumo de productos y servicios en un mercado capitalista y mostrando súbitamente una gran confianza en que la autocomplementación de los individuos - a través de dicho consumo- es suficiente para la generación de atmósferas humanas. Lo colectivo, por su parte, sólo recibe atención bajo las formas de la masa reunida ante el espectáculo o el congreso técnicamente administrado (Sloterdijk, [2004] 2009b: 459-509).

La elección de los ejemplos concretos de generación esférica que se analizan en Esferas III muestra una sesgada preferencia por el contexto de las sociedades ricas: el departamento unipersonal plenamente acondicionado como espacio de autocomplementación y autocuidados posibilitados por

\footnotetext{
${ }^{18}$ Los cinco años transcurridos entre el segundo (1999) y el tercer volumen de Esferas (2004) - mientras que entre el primero y el segundo pasó sólo un año- podrían sugerir un cambio en los intereses del filósofo o incluso que el espíritu que animó originalmente el proyecto se había extinguido. En ese lapso tuvo lugar la polémica mediática y la consolidación de la celebridad del autor, y sus opiniones fueron coincidiendo progresivamente con los intereses de una ideología de derecha.

${ }^{19}$ Ya Vásquez Rocca ha llamado la atención sobre un cambio en el ánimo de Sloterdijk al indicar que quien antes "se inquietaba por la desaparición del humanismo erudito, hoy hace alarde de un optimismo sorprendente" (Vásquez, 2007: 86).

${ }^{20}$ Prácticamente la totalidad del tercer y último capítulo de Esferas III se dedica a argumentar que el lujo es la "línea fundamental evolutiva de la antropogénesis” (Sloterdijk, [2004] 2009b: 571).
}

diversos artefactos -electrodomésticos, espejos, telecomunicaciones, infraestructura de servicios-, la nave espacial como ideal de creación de interioridad radical mediante tecnología de punta, la arquitectura contemporánea como campo de experimentación con la configuración de los espacios físicos o bien las vanguardias artísticas como modalidades de nuevas formas de subjetividad.

Ello revela un punto ciego en la visión de Sloterdijk que le impide concebir mecanismos de procuración de inmunidad en contextos de limitación como formas legítimas de una esferopoiesis en la espuma. Un pasaje en el que menciona las viviendas precarias hechas con materiales de desecho en los cinturones de miseria de las ciudades del tercer mundo es por demás esclarecedor en este sentido. Tras afirmar que éstas son la materialización efectiva de una concepción arquitectónica vanguardista respecto de la vivienda - como machines à habiter -, agrega que en ellas "sólo domina ya la esperanza difusa de la llegada de ayuda extraña sin la perspectiva de un producto que va madurando por sí mismo, que libera y permite llevar una existencia en tiempo propio" (Sloterdijk, [2004] 2009b: 430-432).

Así, para Sloterdijk fuera del "gran invernadero [de la concentración capitalista de los privilegios] dominan a menudo condiciones que sólo pueden describirse como negación del potencial humano" (Sloterdijk, [2004] 2009b: 664) y por tanto no son tenidas en cuenta para pensar en la dinámica y arquitectura de las espumas. Por ello, la gran diversidad y pluralidad entre las esferas que las conformarían - aunque se insista en ellas en ciertos apartados del tercer volumen - se ve diluida ante la imagen simplificada de un mundo conformado por microesferas homogéneas de un solo habitante/consumidor y la regeneración esférica ya no se apoya, como antes, en la solidaridad y la vida común. Es innegable que el desarrollo acelerado del lujo - con base en la tecnología contemporánea-y su democratización - principalmente en las sociedades ricas - poseen un carácter normativo para las transformaciones modernizantes y globalizadoras en todo el 
planeta. ${ }^{21}$ No obstante, una comprensión cabal de los tiempos actuales no puede basarse sólo en la atención al contexto en que esos procesos tienen plenamente lugar sin tomar en cuenta las zonas de las que son excluidos o donde ocurren de forma limitada, así como las relaciones entre ambas.

La atención a fenómenos en un contexto distinto alque Sloterdijk da preferencia, como Latinoamérica, puede contribuir a paliar las limitaciones de sus planteamientos. En ésta el acceso al lujo no se ha generalizado al mismo grado, se encuentra menos extendida la vivienda unipersonal y persisten formas de comunidad premodernas, aunque transformadas. Dicho de otro modo, el proceso de modernización se ha sucedido de una manera menos homogénea y por tanto es más palpable una heterogeneidad multitemporal o una simultaneidad de temporalidades históricas (García Canclini, 1990: 70, 235). Es evidente que la caracterización simplista de las microesferas que conforman espumas no responde a la realidad cultural latinoamericana. Pero la idea de que los sectores pobres se encuentran en una situación completamente exterior y desconectada del funcionamiento del gran invernadero del mercado global también es inexacta.

Los productores artesanales mexicanos que incursionan en sistemas de comercialización urbanos y capitalistas estudiados por García Canclini ([1982] 2007), los mercados informales latinoamericanos que forman parte de lo que Ribeiro (2007) llama "globalización popular" o la formación de comunidades y mundos de vida en sectores marginados de ciudades latinoamericanas a partir de la escucha de grabaciones comerciales de cumbia, como es el caso regiocolombiano de Monterrey (Olvera, 2005; Blanco, 2008), son fenómenos culturales específicos que, entre otros, podrían aportar interesantes elementos de análisis. En todos ellos existe una relación desde cierta exterioridad con la "interioridad"

\footnotetext{
${ }^{21}$ Basta considerar, por ejemplo, que el acceso a agua potable, hoy considerado un derecho universal, hace poco más de un siglo estaba disponible para una escasa minoría.
}

global capitalista, pueden observarse procesos de generación y mantenimiento de esferas inmunitarias que no responden a las monósferas de autoemparejamiento o de lujo exacerbado, pero aun así es posible comprender su relación con otras esferas desde los principios del modelo de la espuma.

Ello exige, sin embargo, que se recupere y se desarrolle el potencial de complejidad del modelo, no sólo considerando una mayor diversidad de burbujas susceptibles de conformar una espuma concreta, sino también explorando otras posibilidades de investigación. Por ejemplo, los elementos de intercambio o compartidos por esferas distintas —un producto, un contenido cultural simbólico, un dispositivo tecnológico, etc. - como la concretización de las paredes que las coaíslan, o bien la apropiación por los medios masivos de contenidos originados en una cultura minoritaria o marginal, como ocurre a menudo con la música, como una forma de traslado y amplificación de la interioridad climatizada en un contexto comunitario hacia otros más individualizados - lo que bien podría representar una forma, distinta a la autocomplementación, de mantener las esferas aparentemente individuales-, o incluso la posibilidad de surgimiento de burbujas que, aunque sea de manera provisional y frágil, engloben a otras de menor magnitud. Especialmente interesante resultaría el estudio del surgimiento de atmósferas de inmunidad cultural como respuesta a la limitación técnica o de recursos, una posibilidad que bien puede estar sugerida en la definición que Sloterdijk hace de la espuma como "aire para respirar en un lugar inesperado" (Sloterdijk, [2004] 2009b: 547).

Las posibilidades recién propuestas - que evidentemente requieren una elaboración más amplia que tendría que ser llevada a cabo en otro espacio-, sin desechar la teoría esferológica en sus líneas y conceptos generales, puede contribuir a delinearla de modo que presente una validez más extendida para el estudio cultural. Puede asimismo propiciar el despliegue de implicaciones diversas, que en la esferología, como ha sido desarrollada por su autor, 
se encuentran aún en estado embrionario, sobre todo en lo referente al modelo de la espuma. Esta consideración de las potencialidades y las limitaciones de Esferas pretende, además, superar el tono primordialmente abstracto y especulativo que ha tenido la reflexión sobre esta obra. Pues aun cuando ha sido reconocida como fértil para la comprensión de la realidad contemporánea, hasta ahora sus aportaciones para orientar estudios concretos de fenómenos culturales o sociales ${ }^{22}$ han sido poco aprovechadas. Para modificar esta tendencia se requiere cierto trabajo de elaboración y estructuración de sus contenidos a fin de ampliar sus posibilidades de aplicación, a lo que se ha buscado abonar con este trabajo y a lo que seguramente contribuirán libros introductorios a la obra de Sloterdijk de reciente aparición. ${ }^{23}$ Sin embargo, aun cuando uno de los principales obstáculos para ello ha residido en gran parte en la naturaleza de su redacción y sus referencias, es justo a través de éstas como se despliegan en buena medida sus características ontológicas y epistemológicas más importantes, las cuales podrían verse diluidas al pretender su simplificación. Es por ello que su lectura directa - o la de sus traducciones al español, que son de gran calidad - sigue siendo aconsejable para quien se interese por el pensamiento de este peculiar filósofo.

\section{Referencias bibliográficas}

Bachelard, Gaston, [1957] 2011, La poética del espacio, Fondo de Cultura Económica, México.

Bauman, Zygmunt, 2000, Liquid Modernity, Polity Press, Cambridge.

Blanco, Darío, 2008, "La cumbia como matriz sonora de Latinoamérica. Los colombias de Monterrey", tesis doctoral, El Colegio de México, México.

\footnotetext{
${ }^{22}$ Entre las escasas excepciones se encuentran Welcome to the Desert of the Real (Zizek, 2002) y Foamy Business: On the Organizational Politics of Atmospheres (Borch, 2011).

${ }^{23}$ In Media Res. Peter Sloterdijk's Spherological Poetics of Being (2011) y Sloterdijk Now (2012) fueron publicados por la Amsterdam University y por Polity Press, respectivamente.
}

Borch, Christian, 2011, "Foamy Business: On the Organizational Politics of Atmospheres", en Schinkel Willem y Liesbeth Noordegraaf-Eelens (eds.), In Media Res. Peter Sloterdijk's Spherological Poetics of Being, Amsterdam University Press, Ámsterdam.

Castells, Manuel, [1996] 2001, La era de la información, Siglo XXI, México.

Castro, Luis, 2005, “¿En qué espacio habitamos realmente los hombres?", en Revista de Estudios Sociales, núm. 22, Universidad de los Andes, pp. 89-98.

_ 2009, "Bubbles, Globes, Wrappings and Plektopoi: Minimal Notes to Rethink Metaphysics from the Standpoint of the Social Sciences", en Environment and Planning D: Society and Space, vol. 27, núm. 1, pp. 87-104.

Elden, Stuart (ed.), 2012, Sloterdijk Now, Polity Press, Cambridge.

y Eduardo Mendieta, 2009, "Being-with as Making Worlds: The 'Second Coming' of Peter Sloterdijk", en Environment and Planning D: Society and Space, vol. 27, núm. 1, pp. 1-11, en línea: <http://dro.dur.ac.uk/ $6822 />$.

Fehrmann, Silvia, 2001, "El nuevo zoológico humano", en Página 12, en línea: <http://www.pagina12.com.ar/2001/ suple/Libros/01-03/01-03-11/nota.htm >.

García Canclini, Néstor, [1982] 2007, Culturas populares en el capitalismo, Grijalbo, México.

, 1990, Culturas híbridas. Estrategias para entrar y salir de la modernidad, Grijalbo, Consejo Nacional para la Cultura y las Artes, México.

Gehlen, Arnold, [1940] 1987, El hombre: su naturaleza y su lugar en el mundo, Sígueme, Salamanca.

Gould, Stephen, [1977] 2010, Ontogenia y filogenia, Crítica, Barcelona.

Heidegger, Martin, [1927] 2009, Ser y tiempo, Trotta, Madrid.

, [1954] 2001, Conferencias y artículos, Serbal, Barcelona.

Latour, Bruno, 1994, “On Technical Mediation: Philosophy, Sociology, Genealogy”, en Common Knowledge, vol. 3, núm. 2, pp. 29-64.

2010, "A Plea for Earthly Sciences", en Judith Burnett, Syd Jeffers y Graham Thomas (eds.), New Social Connections, Palgrave Macmillan, Hampshire, Nueva York, pp. 72-84.

Olvera, José Juan, 2005, Colombianos en Monterrey, Consejo Nacional para la Cultura y las Artes, Consejo para la Cultura y las Artes de Nuevo León, Monterrey.

Pérez Gay, José María, 2010, "El Aleph de Peter Sloterdijk”, en Revista de la Universidad de México, Universidad Nacional Autónoma de México, núm. 75, pp. 6-19. 
Poch, Rafael, 2009, "Honeth contra Sloterdijk, la pelea de los filósofos alemanes", en La Vanguardia, en línea: $<$ http://www.lavanguardia.com/cultura/noticias/2009 1004/53796804662/honneth-contra-sloterdijk-la-pelea-de-los-filososos-alemanes-estado-karlsruhe-francfort-escuela-jurg.html>.

Ribeiro, Gustavo, 2007, "El sistema mundial no hegemónico y la globalización popular", en Anuario de Estudios en Antropología Social 2006, Buenos Aires, pp. 7-19.

Safranski, Rüdiger, [2003] 2009, “Prólogo”, en Peter Sloterdijk, Esferas I. Burbujas: microsferología, Siruela, Madrid.

Schinkel, Willem y Liesbeth Noordegraaf-Eelens (eds.), 2011, In Media Res. Peter Sloterdijk's Spherological Poetics of Being, Amsterdam University Press, Ámsterdam.

Sloterdijk, Peter, 1998, Extrañamiento del mundo, Pretextos, España.

_ , [1999] 2000, Normas para el parque humano, Siruela, Madrid.

[1999] 2004, Esferas II. Globos: macroesferología, Siruela, Madrid.

_, [1993] 2008, En el mismo barco, Siruela, Madrid. , [1998] 2009a, Esferas I. Burbujas: microesferología, Siruela, Madrid.

- [2004] 2009b, Esferas III. Espumas: esferología plural, Siruela, Madrid. y Hans-Jürgen Heinrichs, [2001] 2004, El sol y la muerte, Siruela, Madrid.

Solares, Ignacio, 2010, "Editorial”, en Revista de la Universidad de México, núm. 75, Universidad Nacional Autónoma de México, p. 3.

Thrift, Nigel, 2009, "Different Atmospheres: of Sloterdijk, China, and Site", en Environment and Planning D: Society and Space, vol. 27, núm. 1, pp. 119-138.

Tuinen, Sjoerd van, 2009, "Air Conditioning Spaceshipearth: Peter Sloterdijk's Ethico-aesthetic Paradigm", en Environment and Planning D: Society and Space, vol. 27, núm. 1, pp. 105-118.

Vásquez Rocca, Adolfo, 2007, "Peter Sloterdijk, del pesimismo metodológico al cinismo difuso de nuestras sociedades exhaustas", en Konvergencias, Revista de Filosofía y Culturas en Diálogo, año 4, núm. 15, pp. 84-92.

, 2008, "Peter Sloterdijk: espumas, mundo poliesférico y ciencia ampliada de invernaderos", en Nómadas. Revista Crítica de Ciencias Sociales y Jurídicas, Universidad Complutense de Madrid, vol. 18, núm. 2, pp. 315-322, en línea: <www.ucm.es/info/nomadas/18 /avrocca.pdf $>$.

Zizek, Slavoj, 2002, Welcome to the Desert of the Real, Verso, Londres. 